\title{
O valor (in)estimável da Ciência Básica em tempo de pandemia
}

\author{
https://doi.org/10.21814/uminho.ed.24.13
}

\section{Sandra Paiva}

Sandra Paiva (ORCID: 0000-0003-2270-4546) é Professora Auxiliar no Departamento de Biologia da Escola de Ciências da Universidade do Minho, investigadora do Centro de Investigação em Biologia Molecular e Ambiental e membro do Conselho Geral da mesma Universidade. Durante o seu doutoramento foi estudante visitante nas Universidades de Paris, Madrid e Amsterdão. Foi Professora Visitante na Universidade de Califórnia, Berkeley, como bolseira FLAD e Fulbright. Entre 2010 e 2016 foi Vice-Presidente da Escola de Ciências da Universidade do Minho. 


\section{O VALOR DA CIÊNCIA BÁSICA E O SARS-CoV-2}

A pandemia causada pelo vírus SARS-coronavirus 2 (SARS-CoV-2) chegou repentinamente tendo revolucionado todos os aspetos da nossa vida, tal como a conhecíamos até então. A esperança de normalidade, de uma nova normalidade, conceito que já aceitámos como certo, reside nas respostas que possam surgir da Ciência: uma vacina, fármacos antivirais, tratamentos com anticorpos. Muitos não compreendem como é possível que, numa era de tantos avanços científicos, a Ciência demore tanto tempo a dar respostas imediatas. E é aqui que urge falar da Ciência Básica ou Fundamental, que procura desvendar e detalhar os processos, os mecanismos, permitindo que exista e se expanda a Ciência Aplicada. Ainda que não se deva estabelecer uma fronteira entre ambas, muitos defendem o protagonismo da Ciência Aplicada em detrimento da Ciência Básica, tendo claramente dificuldades em compreender, principalmente, o tempo do processo científico. Mas como elucidar, transmitir esta relevância, como convencer o grande público, decisores políticos, empresários, que a Ciência Básica é essencial para o progresso e desenvolvimento tecnológico? Há tantos bons exemplos em que a Ciência Básica oferece benefícios bastante esperados, que esta deveria realmente ser uma ideia fácil de "vender". Um bom exemplo é a tecnologia que levou à revolução na edição de genoma, a tecnologia CRISPR, que muitas pessoas conhecem, apesar de não perceberem os detalhes. Muitas delas ficariam surpresas ao saber que tudo partiu de investigação em microbiologia básica, realizada por um grupo de investigação em Espanha, outro na Europa Oriental e dois cientistas a trabalhar num laboratório de uma empresa de iogurtes na Dinamarca, apenas a tentar compreender como é que as bactérias combatem os vírus que as infetam. Ninguém realmente poderia imaginar que esse entendimento levaria a esta revolução. Aproveito para sublinhar que esta fortuitidade - encontrar-se, por acaso, uma coisa que não se procura, que tem o nome fantástico de serendipidade - é também uma das maravilhas da investigação fundamental, pois estamos disponíveis para observar com rigor o que acontece e não tanto empenhados em obter um determinado resultado final. Atualmente, a procura de um tratamento eficaz contra a COVID-19, a doença causada pelo SARS-CoV-2, é dificultada pela falta de conhecimento sobre a Biologia Celular básica da infeção. 


\section{A BIOLOGIA BÁSICA DO SARS-CoV-2}

O meu grupo de investigação estuda um processo fundamental em todas as células de eucariontes, como o Homem, o processo de tráfego intracelular de proteínas, usando como organismo modelo um microrganismo, a levedura responsável pelo fabrico do pão e da cerveja. Em particular, pretendemos identificar os sinais e as vias que conduzem à degradação de transportadores de nutrientes que se localizam na membrana plasmática, que é a fronteira das células com o meio circundante. Para estas proteínas serem degradadas têm que ser internalizadas em vesículas, por um processo celular designado por endocitose (Figura 1). Se esta via de tráfego endocítico estiver, de alguma forma, alterada e a destruição proteica não se processar adequadamente e no tempo certo, estas proteínas podem acumular-se na membrana plasmática e causar danos nas células levando a patologias várias, como cancro e doenças neurodegenerativas. Por outro lado, vírus como o Influenza ou HIV usam alguma da maquinaria envolvida nestas vias de tráfego intracelular, em particular na via de endocitose, para penetrar a sua informação genética (DNA ou RNA) nas células, por fusão do invólucro membranar do vírus com a membrana plasmática das nossas células. Este exemplo de investigação fundamental, na área da Biologia Celular, relaciona-se intimamente com o novo Coronavírus.

Sabe-se que este vírus parece exigir endocitose como mecanismo de entrada nas células humanas, e essa endocitose deve estar associada à proteína ACE2 (abreviatura da designação em inglês, angiotensin-converting enzyme 2), um recetor localizado na membrana plasmática das células humanas, ao qual a proteína spike (S), existente à superfície do vírus, se liga, num modelo tipo chave-fechadura (Figura 1). 


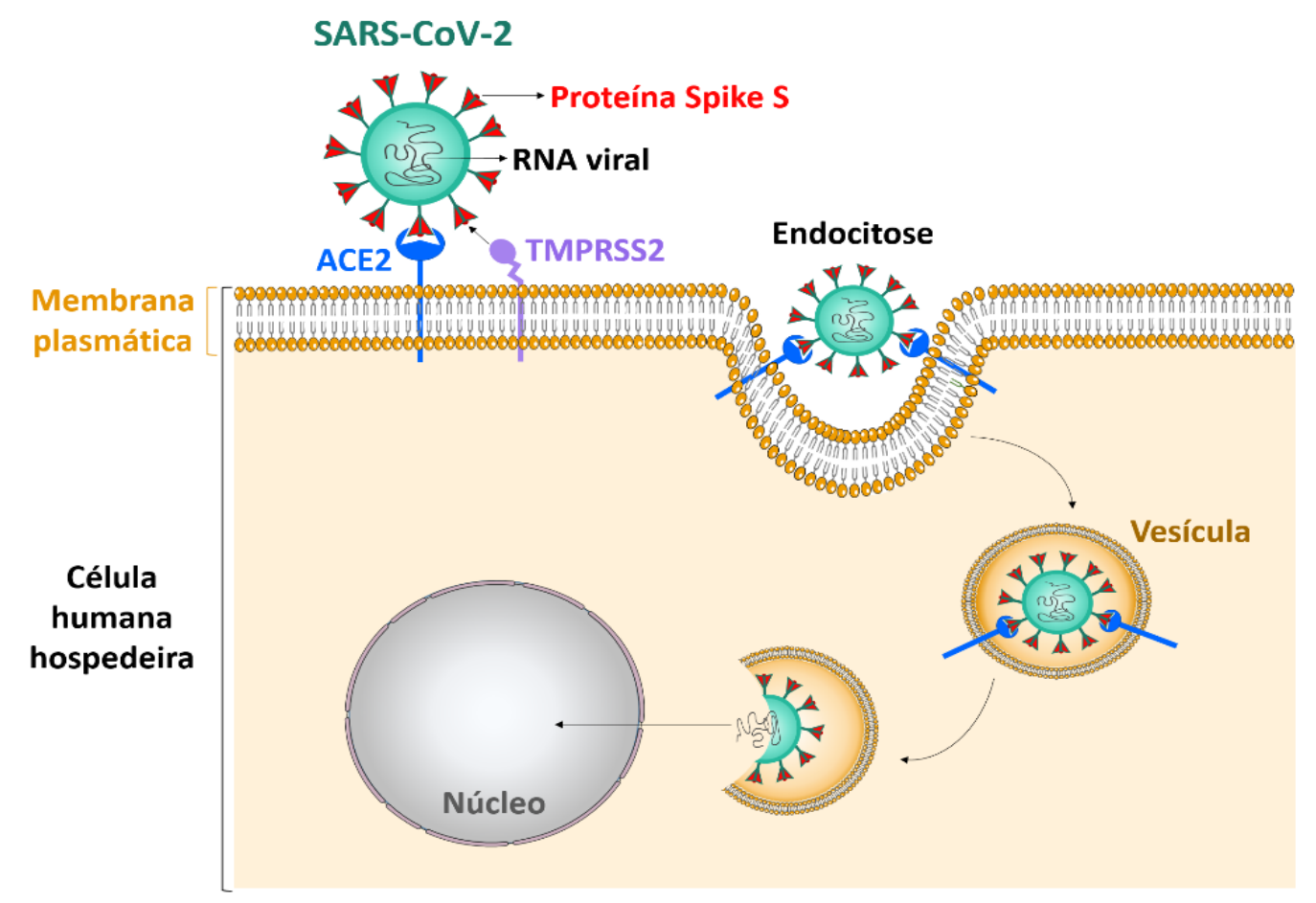

Figura 1. Modelo de infeção do vírus SARS-CoV-2 em células humanas.

A maquinaria celular que vai ser mobilizada por um vírus como o SARS, HIV ou Influenza é a mesma maquinaria que a célula usa para funcionar, se construir e multiplicar, e o vírus aprendeu habilmente a explorar essa maquinaria. Portanto, se entendermos toda a mecânica básica de como uma célula se constrói, como a membrana celular se constrói, aprenderemos como o vírus consegue explorar estes processos.

Em plena pandemia, lecionei online, para alunos de pós-graduação, a 5 Edição do curso avançado "Degradação e Tráfego Intracelular de Proteínas na Saúde e na Doença”, tendo discutido, entre muitos outros assuntos, a relevância médica de se conhecerem em pormenor os mecanismos moleculares subjacentes a processos básicos das células. Numa sessão de "Career Development and BioScience Research", organizada no âmbito do curso, tivemos a oportunidade de conversar com os Professores Alexander Sorkin (Escola de Medicina, Universidade de Pittsburgh, U.S.A.) e Christopher G. Burd (Yale Medical School, Universidade de Yale, U.S.A.), peritos internacionais na área do Tráfego Intracelular (Figura 2). 


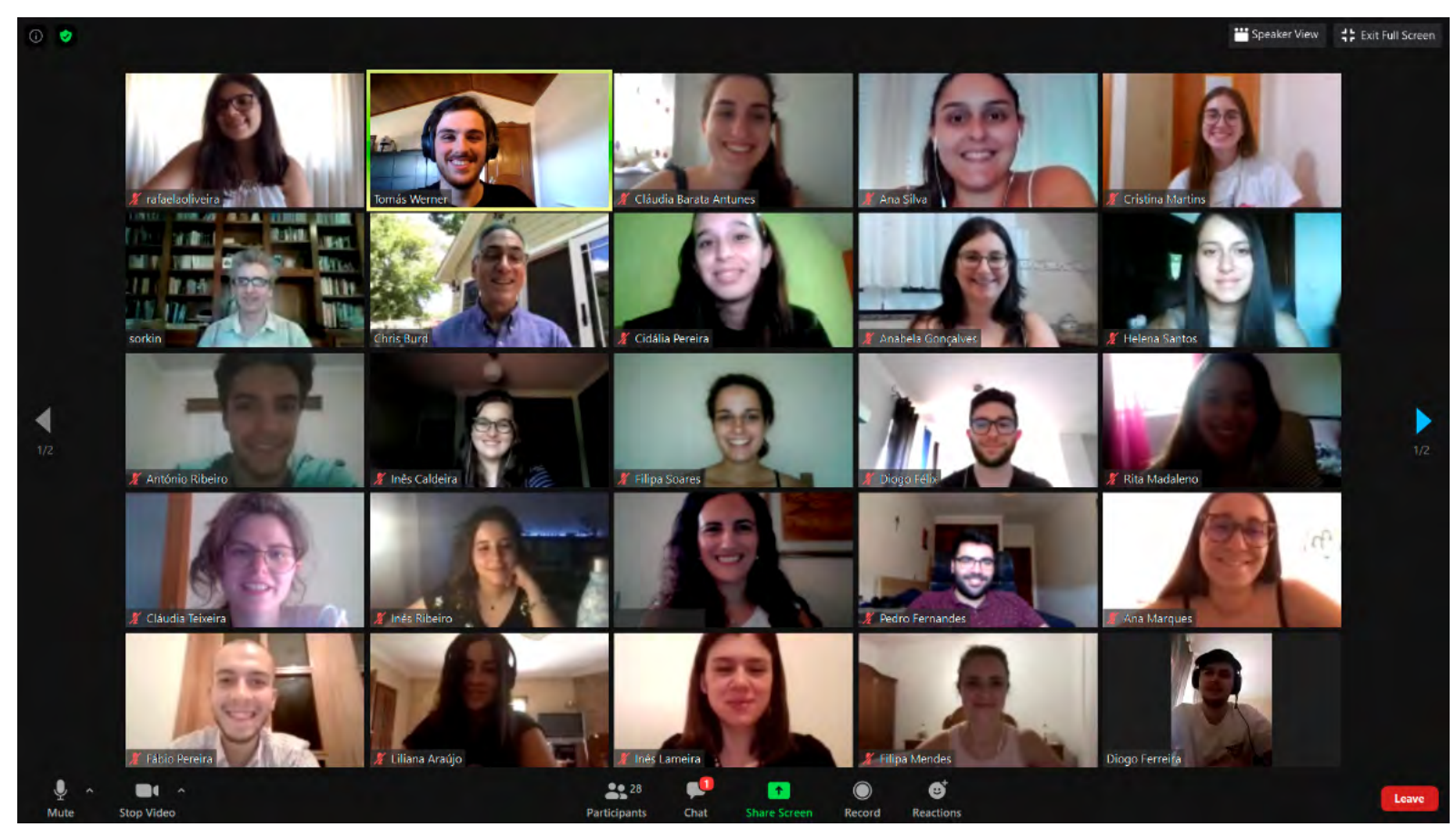

Figura 2. Imagem da sessão de "Career Development and BioScience Research".

O Professor Sorkin relatou como parte da sua investigação, de cariz essencialmente fundamental, estava a ser direcionada no sentido de compreender melhor a localização e tráfego subcelulares do recetor ACE2, bem como de uma protease chave, a TMPRSS2 (Figura 1), localizada também na membrana plasmática das nossas células e essencial para a ativação do vírus. É sua convicção que, mais importante do que determinar os níveis celulares totais destas proteínas, é essencial perceber a sua quantidade à superfície celular.

O Professor Burd relatou que o seu laboratório encerrou dia 17 de março de 2020 devido à pandemia e que o governador do Estado em que vive também ordenou medidas de confinamento. À medida que os dias se transformavam em semanas, e semanas em meses, começou a pensar em como poderia contribuir para combater o vírus. Chegou à conclusão de que a melhor maneira de ajudar seria fazer o que sabe fazer melhor - pesquisar sobre a biogénese de organelos (estruturas subcelulares vitais para o funcionamento da célula eucarionte). Acontece que os coronavírus também sequestram um organelo designado retículo endoplasmático e fazem com que este seja remodelado num organelo de replicação, permitindo que se produzam grandes quantidades 
de novos vírus, sem dúvida contribuindo para a virulência. Quase nada se sabe sobre esse processo para nenhum coronavírus, e esse é exatamente o problema biológico celular que estuda, com a sua equipa, há mais de 25 anos. Assim, em conjunto com dois dos seus colegas de Yale, um dos quais virologista, criaram um plano para redirecionar parte dos seus laboratórios para a pesquisa de SARS-CoV-2. O seu objetivo é descobrir como o SARS-CoV-2 condiciona a formação de organelos de replicação, podendo, assim, expor vulnerabilidades para a replicação do vírus e apoiar novas terapêuticas. Será vital que as agências financiadoras reconheçam o valor real da pesquisa fundamental para entender como o SARS-CoV-2 infecta as pessoas e as consequências da infeção.

“Como é que este vírus de RNA se replica nas nossas células?” é uma de muitas questôes que persistem, cujas respostas são diretamente relevantes para a manutenção da saúde pública, e que importa perseguir sem descanso.

\section{UMA PANDEMIA ANUNCIADA E O PODER DA COMUNICAÇÃO DE CIÊNCIA}

Em 2003, Andrea Gambotto e seus colaboradores, da Universidade de Pittsburgh, estiveram muito perto de desenvolver uma vacina contra o vírus SARS-CoV, que tem muitas semelhanças com o SARS-CoV-2. Uma vez que aquela epidemia foi rapidamente controlada o financiamento para avançar para ensaios clínicos não foi aprovado. Agora os mesmos investigadores estão envolvidos num esforço internacional para desenvolver uma vacina candidata, designada por PittCoVacc (1), beneficiando de muita da investigação que foi desenvolvida em 2003. Existem outras histórias semelhantes a esta, no entanto, se os ensaios clínicos da altura tivessem avançado, poderíamos já estar um passo à frente, tendo, por exemplo, um melhor conhecimento sobre as estratégias a adotar para mitigar potenciais efeitos adversos da vacina. Estudos que indicam que anticorpos contra o vírus podem desencadear uma doença imune aumentada, quer pelo aumento de infeção nas células alvo quer pelo aumento da inflamação e gravidade da doença pulmonar, são razão suficiente para que não se ultrapassem etapas e que se mantenham os financiamentos, mesmo quando as epidemias não evoluem. 
A Universidade de Pittsburgh é a mesma onde, há mais de 50 anos, Jonas Salk desenvolveu a vacina contra a poliomielite, numa altura em que nos Estados Unidos a crença na vacinação e na Ciência talvez fosse maior do que na atualidade. $\mathrm{Na}$ verdade, um dos grandes desafios, e que se tornará ainda mais importante, diria vital, nos próximos meses, é derrubar a forte resistência e desconfiança em relação à vacinação, que são contraditórias a todas as evidências dos benefícios. Na verdade, não é por falta de provas e argumentos científicos sólidos. O que dificulta a mensagem é uma falta generalizada de conhecimento do grande público sobre infeçôes e sobre o sucesso de vacinas que salvam "silenciosamente" muitos milhóes de pessoas em todo o mundo, havendo assim muita ignorância que se perpetua e que, infelizmente, pode ser aproveitada, como todas as formas de ignorância podem. Precisamos de porta-vozes qualificados que possam falar com essas pessoas, numa linguagem simples e acessível, mas eficaz, tornando-as assim mais conhecedoras e, portanto, menos apreensivas. Existem alguns opositores comprometidos que nunca serão convencidos, mas a maioria das pessoas só precisa de alguém em quem possa confiar para aceitar e entender esses conhecimentos.

\section{AS VOZES DA CIÊNCIA}

Sem querer abrir dicotomias, porque todas as áreas se interpenetram, penso que a defesa da Ciência Básica deverá ser um desígnio comum e envolver o maior número possível de atores. Por considerar que as vozes de peritos consagrados são essenciais para a causa da Ciência Básica, reuni um conjunto de entrevistas a cinco cientistas, três dos quais detentores de um Prémio Nobel. São eles Peter J. Ratcliffe, Margaret S. Robinson, Jorge Paiva, Ada E. Yonath e Randy Schekman. A todos pedi que respondessem às três seguintes questões:

1) Como podemos justificar, em tempos de crise, o investimento em investigação fundamental na área das Biociências quando há demanda por soluções imediatas?

2) Qual o impacto futuro desta crise no financiamento da investigação fundamental e na investigação científica em geral?

3) Momentos como esse fortalecem ou enfraquecem a visão de que a Educação Pública deve ser promovida? Porquê? 
Segue-se um breve resumo da biografia de cada um destes cientistas e as suas respostas, umas mais elaboradas do que outras, às questóes anteriores.

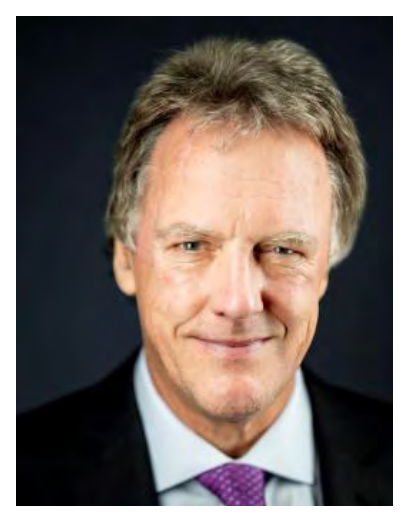

Sir Peter J. Ratcliffe (PR) é um médico e cientista britânico, Professor na Universidade de Oxford, Diretor de Investigação Clínica do Instituto Francis Crick, no Reino Unido, tendo recebido em 2019 o Prémio Nobel da Fisiologia e Medicina, juntamente com William Kaelin Jr. e Gregg L. Semenza. O seu trabalho contribuiu para desvendar como é que as nossas células sentem e se adaptam a niveis baixos de oxigénio, e abriu o caminho para o desenvolvimento de novas estratégias para combater a anemia e outras doenças como o cancro.

PR 1: O argumento sobre o gasto de recursos em Ciência Básica deve ser claro. Todos os métodos que estamos a usar para detetar o SARS-CoV-2, por exemplo PCR, isolamento de RNA, métodos de sequenciação para acompanhar a epidemiologia viral, anticorpos para testar se os indivíduos foram expostos, foram desenvolvidos sem qualquer conhecimento do problema atual. Portanto, a posição contrasta favoravelmente com o que aconteceu em 1918, quando essas tecnologias não estavam disponíveis para lidar com a pandemia de Influenza. Claramente, pode haver um requisito para agrupar o conhecimento e as tecnologias existentes em busca de soluções mais a curto prazo, mas isso não deve prejudicar o valor da investigação fundamental e a sua aplicação a problemas futuros imprevistos.

PR 2: Acredito que a crise mudará a visão do financiamento da investigação, mas que isso não será à custa de toda a Ciência Básica. Uma coisa que será enfatizada brutalmente é o risco de que uma epidemia ocorra com uma taxa de mortalidade muito maior, do que foi registrado com o SARS-1 e MERS. Eu imagino que a liderança política e científica se torne ciente dessa ameaça rapidamente e que fundos públicos adicionais sejam usados efetivamente para criar um melhor estado de preparação. 
PR 3: Estes momentos fortalecem, claramente, a visão de que a educação pública deve ser apoiada. A assimilação e a gestão da base do conhecimento são essencialmente a função fundamental da educação, e sem isto tudo estaria perdido.

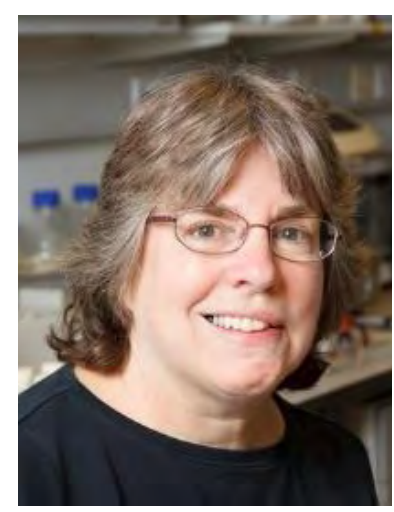

Margaret S. Robinson (MR) é uma Bióloga Molecular Britânica, Professora e Investigadora no Cambridge Institute for Medical Research, da Universidade de Cambridge, Reino Unido. Do seu trabalho destaca-se a identificação de proteinas adaptadoras localizadas na superficie de vesiculas revestidas. Alguns destes adaptadores estão mutados em algumas doenças genéticas.

MR 1: Eu diria que a razão pela qual o mundo foi capaz de responder tão rapidamente a esta situação foi por causa da Ciência Básica. Veja como o SARS-CoV-2 foi isolado tão rapidamente e o seu genoma sequenciado. As micrografias eletrónicas das células infetantes do vírus foram publicadas em janeiro de 2020, fornecendo aos biólogos celulares pistas importantes sobre sua captação e libertação. É claro que é importante financiar Investigação Aplicada, como o desenvolvimento de vacinas, mas todos os estudos sobre o vírus, incluindo os mais aplicados, são baseados em investigação fundamental.

MR 2: Estou certa de que algumas coisas vão mudar e, em alguns casos, sinto que as mudanças serão benéficas. Eu gostaria de pensar que haverá mais ênfase na investigação colaborativa, em vez de todos estarem a competir entre si. Também haverá mais pressão sobre as revistas científicas para publicar descobertas importantes o mais rápido possível, em vez de fazer com que os autores passem muitos meses a fazer experiências para satisfazer um avaliador em particular, quando por vezes uma mudança no texto é suficiente. E acho que mais reuniões científicas serão uma combinação entre o presencial e o online, o que é melhor para o planeta (tenho colegas que viajavam para uma reunião internacional a cada duas semanas - imagino qual será a sua pegada de carbono!) 
MR 3: Gostaria de pensar que a pandemia atual reforça a visão de que a educação pública deve ser promovida. Cabe a cada indivíduo fazer o possível para se proteger a si e aos outros, bem como tomar decisóes informadas nas urnas. Quanto melhor a educação pública, especialmente na Ciência, mais as pessoas entenderão a lógica por trás dos regulamentos e diretrizes e agirão de acordo, em vez de achar tudo um incómodo.

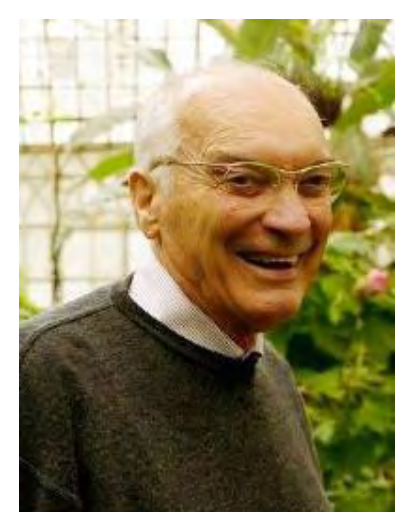

Jorge Paiva é um biólogo português, Professor na Universidade de Coimbra. Considerado um dos maiores peritos em floresta, destacam-se os seus contributos nas áreas da Botânica e Taxonomia, tendo participado em inúmeras expediçôes internacionais a recolher e estudar plantas. É um ativo comunicador de Ciência e defensor do Meio Ambiente e da Biodiversidade.

JP 1: Comparando a mortalidade e controlo desta pandemia com as de pandemias anteriores. Por exemplo, a pandemia da gripe espanhola de 1918 foi muitíssimo mais difícil de debelar e foi muito mais mortífera, porque as Biociências não estavam tão avançadas como atualmente.

JP 2: A comunicação social mostrou claramente o esforço e trabalho dos biocientistas no estudo, tentativa de controlo e combate deste coronavírus. Todos realçaram o empenho e relevância do trabalho destes cientistas, desde governantes, políticos e população. Nunca as Biociências foram tão badaladas e considerada relevante a sua contribuição para a saúde e bem-estar da Humanidade. Cabe agora aos biocientistas continuarem a não se deixarem cair no esquecimento e promoverem debates públicos e divulgação de resultados científicos relevantes para a Humanidade, para que a Ciência seja financiada de modo a ter eficácia e estar sempre apetrechada, de modo a agir rapidamente em qualquer crise.

JP 3: Momentos como este mostram como a Educação Pública é quase nula, por culpa, fundamentalmente, dos governos nacionais e mundiais que não investem em programas de Educação Pública e dos órgãos de Comunicação Social, particularmente as 
Estações de Rádio e as de Televisão, que rarissimamente emitem programa educativos. É fundamental que os contribuintes pressionem as Estações Públicas de Rádio e de Televisão a emitirem programas educativos durante as designadas horas nobres, demasiadamente disponíveis para governantes e partidos políticos. É fundamental reverter esta ocupação política dos tempos de antena nas horas nobres, para horas educativas. Também é necessário pressionar os governantes de modo a alterarem a falta de qualidade educativa dos programas das Estaçôes Públicas, que existem para bem público e não para competirem com programas das Estaçóes privadas.

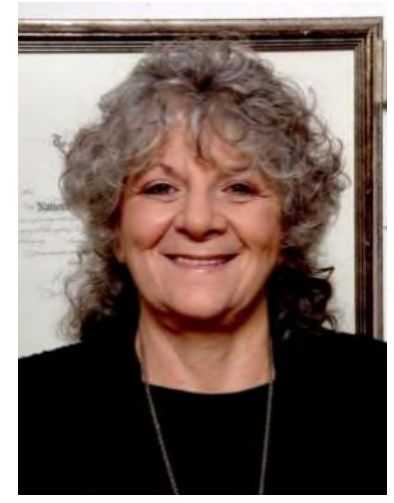

Ada E. Yonatb é Israelita, Professora no Weizmann Institute of Science, em Israel, ganhou o prémio Nobel da Quimica em 2009, juntamente com Venkatraman Ramakrishnan e Thomas A. Steitz, pelos estudos sobre a estrutura e função do ribossoma, local de sintese das proteinas na célula. Estes estudos são relevantes no desenho de novos antibióticos.

AY 1, 3: As necessidades imediatas são importantes, mas uma vez encontrada uma solução, a pesquisa termina. Enquanto a curiosidade conduz a investigação básica, é o caminho para o progresso e o fornecimento de ferramentas científicas para lidar com os próximos problemas.

AY 1, 2: Na verdade não sei. Espero sinceramente que o financiamento para investigação básica continue.

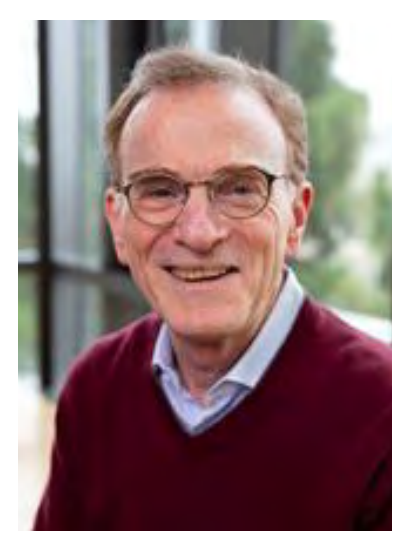

Randy Schekman é biólogo e Professor na Universidade de Califórnia, Berkeley, nos Estados Unidos da América. Em 2013 ganhou o prémio Nobel da Fisiologia e Medicina, juntamente com James E. Rothman e Thomas C. Südhof. Destacam-se os seus trabalbos que conduziram à identificação da maquinaria que regula o tráfego vesicular, um sistema essencial de transporte nas nossas células. Defeitos neste sistema resultam em inúmeras patologias. 
RS 1: A síndrome respiratória aguda grave (SARS) e a síndrome respiratória do Médio Oriente (MERS), epidemias causadas por coronavírus (respetivamente, o SARS-CoV e o MERS-CoV) foram relativamente fáceis de conter pelos métodos tradicionais de saúde pública e, portanto, o investimento na compreensão do coronavírus, no desenvolvimento de inibidores que bloqueiam as enzimas necessárias para a replicação do coronavírus terminou, e a indústria farmacêutica perdeu o interesse porque não havia mercado de vacinas ou medicamentos e isso foi muito míope, porque com dois episódios separados do coronavírus, deveríamos esperar que outro surgisse. De facto, poderíamos esperar que um que surgisse seria muito pior. E se tivéssemos investindo o tempo todo no entendimento básico, teríamos sido capazes de controlar completamente essa pandemia que pouparia triliões de dólares e milhares de vidas. Devido a um investimento míope por parte dos governos e da indústria farmacêutica, estamos a enfrentar este drama que temos agora. Precisamos de continuar a investir à escala mundial, porque esta não será a última vez que uma nova infeção por coronavírus irá emergir da Natureza.

Há outra razão que justifica a investigação em Ciência Fundamental. Por exemplo, o Governo de Portugal poderia dizer: "Sim, concordamos consigo, mas o "European Research Council” e o Governo dos E.U.A. investem muitos milhares de milhões de dólares, muito mais do que podemos investir, porque deveríamos nós, com um orçamento muito mais reduzido, também fazê-lo?”. Uma razão fundamental que defendo é que todos os países, mesmo os pequenos países, querem melhorar a sua base industrial e tecnológica, e para isso precisam investir na formação aos níveis de pós-doutoramento e doutoramento de jovens estudantes nativos do seu país, para que não só continue a Ciência Básica, mas, ainda mais importante, sejam apoiadas as suas indústrias biotecnológicas. A Biotecnologia pode florescer em empresas em qualquer país do mundo e não apenas em países com grandes economias. Deverá haver um investimento em Ciência Básica para construir a infraestrutura intelectual de um país, o que apoiará o crescimento de novas indústrias nesse país criando força económica. Existe uma razão não apenas sob uma perspetiva global, mas também sob uma perspetiva local, para investir em Ciência como base do desenvolvimento industrial.

RS 2: Acho que o financiamento não irá ser afetado. Acho que de fato sofreremos uma contração económica, mas acredito que as pessoas compreenderão a necessidade 
de continuar a investigação, para que não tenhamos uma interrupção como a que estamos a ter. Se, por exemplo, a epidemia SARS se tivesse espalhado mais, as pessoas talvez não tivessem desistido, e os recursos para continuar a compreender a base das doenças infeciosas não tivessem diminuído.

Por outro lado, os jovens que estavam a planear carreiras em áreas das Ciências serão mais encorajados agora a ingressar em áreas de saúde pública e doenças infeciosas, porque se tornou tão óbvio qual é a necessidade. Acho que veremos muito mais pessoas em profissóes relacionadas com a saúde e investigação ambiental e biomédica como resultado desta pandemia.

Relativamente à investigação em geral, este confinamento permitiu que, por exemplo nos Journal Clubs que tenho organizado com o meu grupo de investigação, tivéssemos mais tempo para ler em profundidade os artigos, tivéssemos discussóes muito interessantes, o que resultou em muitas ideias úteis que poderemos aplicar ao nosso trabalho. Em geral pensámos mais claramente sobre o que estamos a fazer, o que beneficiará a nossa investigação quando regressarmos ao laboratório, e este é um exercício útil. As pessoas tiveram mais tempo para refletir sobre o que estão efetivamente a fazer, em vez de se manterem simplesmente ocupadas.

RS 3: A base de todo o conhecimento é ter um eleitorado inteligente e bem informado; não há substituto para isso. Obviamente, isto vem do topo e, quando existem líderes demagogos, torna-se tudo mais difícil. Nos Estados Unidos da América temos o Doutor Anthony Fauci, homem de profunda capacidade e inteligência, que tem sido marginalizado pelo governo. Se um número grande de pessoas desvalorizar o que pessoas como Anthony Fauci dizem, então o progresso será mais difícil. Não há substituto para uma liderança sábia e, é claro, é necessário um esforço consistente e abrangente na educação pública a todos os níveis, tanto nas escolas quanto no público, algo que é caro e difícil e que requer uma liderança realmente inspirada. 
Esta foi a segunda entrevista que tive oportunidade de fazer ao Professor Randy Schekman (2). Desta vez falámos por Zoom, o que também ilustra bem os tempos que vivemos. A primeira vez que conversámos foi em 2015, quando fui Professora Visitante na Universidade de Califórnia Berkeley, como Bolseira FLAD e Fulbright. Na altura, disse-me que tinha mais duas causas para além da defesa da Ciência Básica e Fundamental: a do acesso livre às publicações científicas e a do Ensino Superior Público. Ainda que estas causas se mantenham e sejam mais relevantes do que nunca, contou-me que abraçou uma nova causa, que tem uma relação mais pessoal com a sua vida.

A sua esposa faleceu há quase 3 anos, tendo sofrido de doença de Parkinson durante 20 anos. Quando a esposa ficou mais doente, foi abordado por uma fundação familiar, iniciada por um dos cofundadores do Google Sergey Brin. O Sr. Brin tem investido muito da sua riqueza em investigação relacionada com a doença de Parkinson, pois a sua mãe tem uma forma genética da doença. Decidiu, de maneira independente, que o problema é que simplesmente não entendemos a base mecanística da doença, como ela começa e como progride, de modo que a descoberta de medicamentos não é guiada por alguns princípios fundamentais do que está errado na doença. Assim, quando a esposa faleceu, o Professor Schekman tornou-se o diretor científico de uma organização chamada Aligning Science Across Parkinson's (ASAP), financiada pela Sergey Brin Family Foundation, que fez um grande investimento no desenvolvimento de uma abordagem para a ciência básica da doença de Parkinson. A ASAP começará a financiar os primeiros projetos em outubro de 2020 e um dos objetivos é criar uma rede internacional de equipas de investigadores, que colaboram entre si, para entender a base molecular da doença.

Este é um excelente exemplo como todos, incluindo empresários e empreendedores, podem ser convocados e ter um papel ativo na causa da Ciência Básica.

\section{CONSIDERAÇÕES FINAIS}

Estas são vozes lúcidas e inspiradoras que deverão, certamente, ser amplificadas. Poderemos retirar liçôes valiosas desta pandemia contra a qual, seguramente, haverá uma ou mais vacinas, que estão a ser desenvolvidas num enorme esforço internacional, 
a partir do conhecimento gerado pela Ciência Básica sobre a infeção viral. Acredito que o sucesso desta colaboração científica, envolvendo laboratórios e companhias farmacêuticas de todo o mundo, possa diluir ou erradicar essa noção populista e irrealista de que um país tem que ser totalmente independente. Espero que seja claro para todos que terá sido este esforço científico internacional que permitiu solucionar um problema, que apenas um país não poderia resolver sozinho!

Ainda que haja excelentes porta-vozes da Ciência, temos também que intensificar as nossas vozes para uma educação pública constante sobre o valor da Ciência Básica. Os desenvolvimentos e progressos resultantes fornecem claramente evidências que o futuro é ilimitado!

\section{AGRADECIMENTOS}

Muito obrigada a todos os cientistas que deram o seu contributo e testemunho neste artigo e à Professora Manuela Martins pelo convite que me endereçou. Gostaria de agradecer à Dra. Cláudia Barata-Antunes pelo desenho da Figura 1 e à Sofia Johansson pela edição da Figura 2. Obrigada à Professora Ana Cunha e ao Professor Pedro F. Oliveira pela leitura atenta, sugestóes e revisão do texto final. Um agradecimento à Fundação Luso-Americana, à Embaixada dos EUA em Portugal, à Fulbright Portugal e à FCT pelo financiamento de visitas e estadias de Sandra Paiva nos EUA e de David G. Drubin e Christopher Burd em Portugal.

\section{BIBLIOGRAFIA}

(1) Kim E, Erdos G, Huang S, Kenniston TW, Balmert SC, Carey CD, Raj VS, Epperly MW, Klimstra WB, Haagmans BL, Korkmaz E, Falo LD Jr, Gambotto A. (2020). Microneedle array delivered recombinant coronavirus vaccines: Immunogenicity and rapid translational development. Version 2. EBioMedicine. 55:102743. https://doi.org/10.1016/j.ebiom.2020.102743.

(2) Paiva S e Passos N. (2015). "Entrevista a Randy Schekman, laureado com o Prémio Nobel da Fisiologia e Medicina em 2013 - «É essencial continuar a investir em Ciência»”. Correio do Minho, Rubrica Ciência, 0412-2015. 